\section{(C) OPEN ACCESS}

\title{
Full dose, reduced dose or discontinuation of etanercept in rheumatoid arthritis
}

\author{
Ronald F van Vollenhoven, ${ }^{1,2}$ Mikkel Østergaard, ${ }^{3}$ Marjatta Leirisalo-Repo, ${ }^{4}$ \\ Till Uhlig, ${ }^{5}$ Marita Jansson, ${ }^{6}$ Esbjörn Larsson, ${ }^{6}$ Fiona Brock, ${ }_{1}^{7}$ Karin Franck-Larsson ${ }^{8}$
}

\section{Handling editor Gerd R Burmester}

- Additional material is published online only. To view please visit the journal online (http://dx.doi.org/10.1136/ annrheumdis-2014-205726)

For numbered affiliations see end of article.

\section{Correspondence to} Professor Ronald F van Vollenhoven, Clinical Therapy Research, Inflammatory Diseases (ClinTRID), The Karolinska Institute, Stockholm 17176, Sweden; ronald.van.vollenhoven@ki.se

Received 10 April 2014 Revised 17 March 2015 Accepted 25 March 2015 Published Online First 14 April 2015

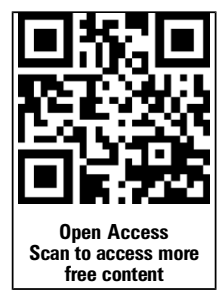

\section{CrossMark}

\section{To cite: van}

Vollenhoven RF,

Østergaard M, Leirisalo-

Repo M, et al. Ann Rheum Dis 2016;75:52-58.

\section{ABSTRACT}

Background The aim of the Dose Reduction or Discontinuation of Etanercept in Methotrexate-Treated Rheumatoid Arthritis Patients Who Have Achieved a Stable Low Disease Activity-State study was to investigate the effect of etanercept (ETN) dose maintenance, reduction or withdrawal on patients with rheumatoid arthritis (RA) who had already achieved stable low disease activity (LDA) on ETN $50 \mathrm{mg}$ +methotrexate (MTX).

Methods Patients with RA $(n=91)$ and stable LDA with ETN 50 mg once weekly (QW)+MTX were included. After 8 weeks with unchanged treatment, 73 patients were randomised in a double-blind design to ETN $50 \mathrm{mg}$ QW+MTX (ETN50), ETN 25 mg QW+MTX (ETN25) or placebo QW+MTX (PBO) for 48 weeks. Patients who flared were declared failures and treated with open-label ETN50 until week 48. The primary outcome was the proportion of patients on ETN50 versus PBO who were non-failures after 48 weeks.

Results The proportion of non-failure patients was significantly lower with ETN50 (52\%; $p=0.007)$ and ETN25 (44\%; $p=0.044)$ versus PBO (13\%). Median time to failure was significantly shorter with PBO (6 weeks) compared with ETN50 (48 weeks; $p=0.001)$ and ETN25 (36 weeks; $p<0.001$ ). The majority of patients who flared regained LDA with open-label ETN50 quickly. Adverse events were consistent with the known side effect profiles of these medications.

Conclusions In patients with established RA who have achieved stable LDA on ETN50+MTX, continuing both is superior to PBO+MTX. Reduced dose ETN was also more effective than $\mathrm{PBO}$ in maintaining a favourable response, suggesting that a maintenance strategy with reduced dose ETN may be possible in a number of patients with established RA.

Trial registration number NCT00858780.

\section{INTRODUCTION}

Rheumatoid arthritis (RA) is one of the most common autoinflammatory diseases, affecting around $0.5-1 \%$ of the adult population in Western countries. ${ }^{12}$ The disease is chronic, affects women three times as often as men and is associated with progressive damage to the bone and cartilage of the joints, decreases in physical function, reduction in health-related quality of life and high societal costs. $^{3-8}$ Over the past 15 years, treatment has changed considerably by the introduction of several antitumour necrosis factor (anti-TNF) biological therapies, which for many patients have provided excellent symptomatic relief. The anti-TNF, etanercept (ETN), is one of the most widely used and has been shown in several randomised clinical trials to be effective and comparatively safe. ${ }^{9} 10$ Klareskog et $a l^{11}$ and Emery et $a l^{12}$ demonstrated that the combination of ETN with the standard antirheumatic drug methotrexate (MTX) provides superior results compared with either medication alone. Bathon et $a l^{13}$ showed ETN $25 \mathrm{mg}$ twice weekly monotherapy was superior to a lower dose of ETN $10 \mathrm{mg}$ twice weekly in patients with active early RA. Moreover, longitudinal analyses have shown that a large majority of patients who achieved a good clinical response with combination ETN and MTX maintain it with continued treatment. ${ }^{14}$ However, both from the individual patient's standpoint, as well as from a societal perspective, it would be advantageous if medication did not need to be continued indefinitely but could either be reduced in dose, or even discontinued, while maintaining a favourable disease activity state. Only limited data have been published addressing this possibility. Botsios et al investigated the effect of a lower dose of ETN (25 mg once weekly $(\mathrm{QW})$ ) on maintaining disease remission (defined as a disease activity score (DAS) <1.6) achieved using the standard ETN $25 \mathrm{mg}$ twiceweekly regimen (study published as a congress abstract). ${ }^{15}$ They showed that many of their patients who received the reduced ETN dose had not flared during the subsequent year. Similar uncontrolled observations have also been published for other anti-TNF agents. ${ }^{16-19}$ In the majority of these studies, anti-TNF discontinuation was generally associated with a flare in disease. Clinical experience suggests that most patients who reintroduce ETN after a temporary interruption regain disease control. Recently, results from the doubleblinded PRESERVE study showed that low disease activity (LDA) could be maintained with half the usual full dose of ETN. ${ }^{20}$ However, the PRESERVE study was conducted in patients who would not necessarily have been treated with an anti-TNF agent in actual clinical practice.

Here we report the clinical results of a randomised, three-armed, placebo-controlled clinical trial in patients with RA who had achieved a stable LDA state with ETN+MTX treatment in regular rheumatology care. In this study, named Dose Reduction or Discontinuation of Etanercept in MethotrexateTreated Rheumatoid Arthritis Patients Who Have Achieved a Stable Low Disease Activity-State (DOSERA), one-third of the patients continued with unchanged (but blinded) medication, one-third 
received a reduced dose of ETN and one-third continued on MTX alone.

\section{PATIENTS AND METHODS}

Adult patients diagnosed with RA were asked to participate if they had been treated with ETN $50 \mathrm{mg}+$ MTX weekly (in one single or two divided doses) for at least 14 months; received it in combination with MTX at a stable dose of $7.5-25 \mathrm{mg} /$ week for at least 4 months before baseline; and had achieved LDA (DAS based on a 28 -joint assessment (DAS28) $\leq 3.2$, erythrocyte sedimentation rate method) at the time of screening. Evidence of LDA at least 11 months prior to the screening visit had to be documented in either the clinical chart or a clinical registry, with no contrary data in the interim. Further details about the sites, inclusion criteria and ethics are provided in the online supplementary text.

\section{Treatment}

Patients who entered the study continued on the same medications, ETN+MTX, for an 8-week run-in period (period 1; figure 1A). The MTX dose was kept unchanged throughout the study. The total weekly dose of ETN was also kept unchanged, but all patients were provided with the once-weekly $50 \mathrm{mg}$ dose in the form of the lyophilised product. For most patients, this entailed a small change from the previously used pre-filled syringe and/or the $25 \mathrm{mg}$ twice-weekly dosage.

Patients were assessed clinically at 4-week intervals, including a 28-joint count, blood tests and patient-reported outcomes.
After 8 weeks, those patients who had maintained a DAS28 $\leq 3.2$ during period 1 were randomised to one of three arms (period 2): ETN $50 \mathrm{mg}$ weekly (unchanged)+MTX (ETN50), ETN 25 mg weekly (reduced dose)+MTX (ETN25), or placebo + MTX (PBO). In all three arms, the patients continued MTX, and other medications, at the same dose.

The patients were assessed every six weeks for 48 weeks in period 2. If a flare occurred during period 2, the patient was withdrawn from this phase. Criteria for exiting the doubleblinded phase were (a) DAS28 $>5.1$; (b) or DAS28 $>3.2$ and an increase of $\geq 1.2$ from baseline; (c) or DAS28 $>3.2$ and an increase in DAS28 of $\geq 0.6$ from baseline on two consecutive visits at least 1-3 weeks apart; (d) or disease progression as determined by either the investigator or disease flare as experienced by the patient (the patient could contact the study site and be given an evaluation within two weeks and be transferred into period 3). The latter criterion was introduced to safeguard the well-being of patients who might experience genuine RA flares without having increases in DAS28. Patients who discontinued period 2 were designated failures in the primary analysis (see below), transferred to the third phase (period 3) and received ETN $50 \mathrm{mg}$ weekly plus MTX. The main purpose of period 3 was to determine whether any flares occurring during ETN tapering or withdrawal could be reversed.

\section{Assessments}

The primary clinical outcome of this study was the comparison of the proportion of non-failure patients in the ETN50 group
Figure 1 (A) Schematic description of the Dose Reduction or Discontinuation of Etanercept in Methotrexate-Treated Rheumatoid Arthritis Patients Who Have Achieved a Stable Low Disease Activity-State study. (B) Patient disposition. ETN, etanercept; MTX, methotrexate; PBO, placebo; QW, once weekly; $R$, Randomise.
A
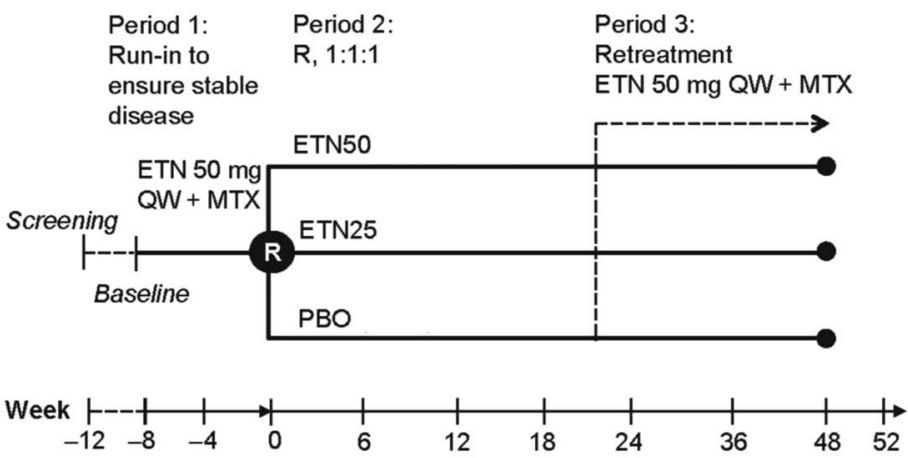

B

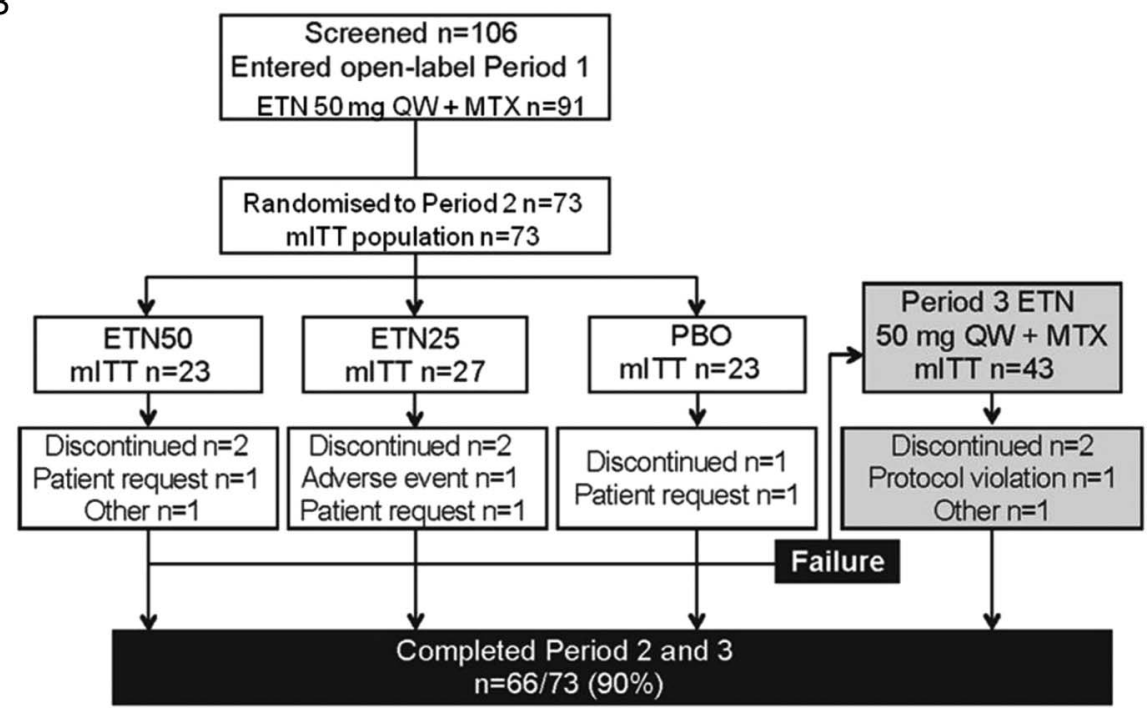


Table 1 Demographics at baseline and disease characteristics at randomisation

\begin{tabular}{|c|c|c|c|c|}
\hline Characteristic & $\begin{array}{l}\text { ETN50 } \\
(n=23)\end{array}$ & $\begin{array}{l}\text { ETN25 } \\
(n=27)\end{array}$ & $\begin{array}{l}\text { PBO } \\
(n=23)\end{array}$ & $\begin{array}{l}\text { Total } \\
(n=73)\end{array}$ \\
\hline Age, years & $53.8(12.1)$ & $59.6(9.2)$ & $56.1(11.5)$ & $56.7(11.0)$ \\
\hline Female gender, n (\%) & $17(74)$ & $18(67)$ & $16(70)$ & $51(70)$ \\
\hline Disease duration, years & $11.5(7.3)$ & $16.6(11.0)$ & $12.3(6.1)$ & $13.6(8.8)$ \\
\hline Rheumatoid factor positive, $\mathrm{n}(\%)$ & $15(68)$ & $18(67)$ & $16(73)$ & $49(69)$ \\
\hline Prior treatment with DMARDs other than MTX, $\mathrm{n}(\%)$ & $15(65)$ & $17(63)$ & $16(70)$ & $48(66)$ \\
\hline Duration of ETN treatment before study start, years & $3.5(1.4)$ & $3.7(1.6)$ & $2.9(1.5)$ & $3.4(1.5)$ \\
\hline DAS28 at start of ETN treatment & $4.9(1.1)$ & $5.2(1.1)$ & $4.8(1.1)$ & $5.0(1.1)$ \\
\hline MTX dose & $12.1(4.3)$ & $14.5(5.0)$ & $15.1(5.4)$ & $13.9(5.0)$ \\
\hline MTX dose, median (min; max) & $10.0(7.5 ; 25.0)$ & $15.0(7.5 ; 25.0)$ & $15.0(7.5 ; 25.0)$ & $15.0(7.5 ; 25.0)$ \\
\hline \multicolumn{5}{|l|}{ Disease characteristics at randomisation } \\
\hline DAS28 remission $(\leq 2.6), \mathrm{n}(\%)$ & $20(91)$ & $21(78)$ & $18(78)$ & $59(82)$ \\
\hline DAS28 LDA (>2.6 to $\leq 3.2), \mathrm{n}(\%)$ & $2(9)$ & $5(19)^{*}$ & $5(22)$ & $12(17)$ \\
\hline DAS28 & $1.9(0.6)$ & $1.9(0.9)$ & $1.9(0.7)$ & $1.9(0.7)$ \\
\hline Swollen joint count & $0.3(0.8)$ & $0.4(0.8)$ & $0.2(0.4)$ & $0.3(0.7)$ \\
\hline Tender joint count & $0.2(0.5)$ & $0.4(0.8)$ & $0.5(0.8)$ & $0.4(0.7)$ \\
\hline Pain VAS & $15.6(18.2)$ & $13.0(10.9)$ & $13.4(10.1)$ & $13.9(13.3)$ \\
\hline HAQ-DI, median (min; max) & $0.25(0.0 ; 1.5)$ & $0.38(0.0 ; 1.5)$ & $0.13(0.0 ; 1.8)$ & $0.25(0.0 ; 1.8)$ \\
\hline SvdH total score & $37.3(41.6)$ & $69.3(68.8)$ & $35.4(30.2)$ & $48.9(53.0)$ \\
\hline SvdH erosion score & $25.1(26.4)$ & $43.6(39.8)$ & $26.2(20.9)$ & $32.5(31.7)$ \\
\hline SvdH joint space narrowing score & $12.1(16.9)$ & $25.7(30.0)$ & $9.2(10.8)$ & $16.4(22.6)$ \\
\hline
\end{tabular}

versus the PBO group. Secondary outcomes included comparison of non-failure patients between the ETN25 and PBO groups; time from randomisation to failure in period 2; and time from failure to LDA/remission (DAS28 $\leq 3.2$ ) in period 3. Remission was defined as DAS28 $\leq 2.6$. Variables at randomisation were investigated as predictors of treatment failure (see online supplementary text). Adverse events (AEs) and serious AEs were recorded throughout the study.

\section{Statistics}

The sample size was estimated on the assumption of a $78 \%$ nonfailure rate for the ETN50 group (based on the findings of a previous study ${ }^{15}$ ). Full details of statistical methodology are provided in the online supplementary text.

\section{RESULTS}

\section{Patient disposition}

A total of 106 patients were screened and 91 patients received at least one dose of ETN in period 1 (figure 1B). A review of the prescreening logs revealed that the most common reasons for patients not proceeding to screening were not being treated with MTX, patient not interested, patient not suitable and disease activity too high. Of the 106 patients screened, 33 were not randomised. Reasons for the screened patients not being randomised were DAS28 $>3.2$ during the open-label period $(n=19)$, patient not able to satisfactorily complete the study $(n=5)$, no active disease at the time of starting ETN $(n=2)$, no current treatment with $\operatorname{MTX}(n=3)$ and other reasons $(n=4)$. Thus, a total of 73 patients were available for randomisation and included in the modified intention-to-treat population. Of these patients, 23 were randomised to the ETN50 group, 27 to the ETN25 group and 23 to the PBO group. Forty-three patients (59\%) failed period 2 and were therefore entered into period 3. Sixty-six patients (90\%) completed periods 2 and 3.
Overall, the mean age was 56.7 (SD 11.0) years, and the mean disease duration was 13.6 (SD 8.8) years (table 1). The mean last dose of MTX at screening was 13.9 (SD 5.0) mg/ week. The majority of patients in each treatment group were in DAS28 remission at randomisation: ETN50 91\%, ETN25 78\% and $\mathrm{PBO} 78 \%$. Although non-significant, the ETN25 group had numerically higher DAS28 and worse radiographic scores at the time of ETN treatment.

\section{Clinical efficacy}

For the primary outcome, the proportion of non-failure patients was significantly greater in the ETN50 group than in the PBO group: $52 \%$ vs $13 \%$ at week $48(\mathrm{p}=0.007$; figure 2$)$. Likewise, the median time to failure was significantly longer in

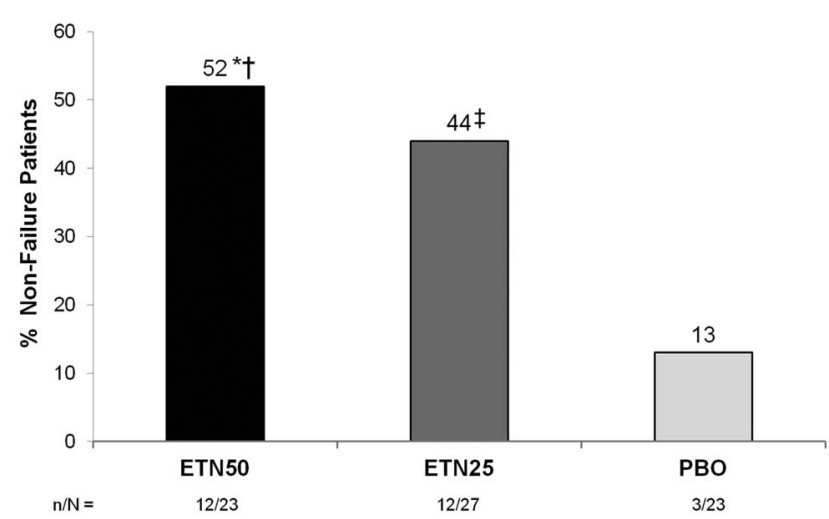

Figure 2 Proportions of non-failure patients in period 2. * $\mathrm{OR} 7.2$ (95\% Cl, 1.7-29.8), $\mathrm{P}=0.007$ vs. PBO; †OR $1.7(95 \% \mathrm{Cl}, 0.5-5.4)$, $\mathrm{P}=0.362$ vs. ETN25; $¥ 0 \mathrm{OR} 4.2(95 \% \mathrm{Cl}, 1.0-17.0), \mathrm{P}=0.044$ vs. $\mathrm{PBO}$. Modified intention to treat population used. $P$ values calculated using GEE analysis. ETN, etanercept; MTX, methotrexate; PBO, placebo. 
the ETN50 group than in the PBO group: 48 vs 6 weeks, $\mathrm{p}=0.001$ (figure $3 \mathrm{~A}$ ). In the ETN25 group, the proportion of non-failure patients $(44 \%, p=0.044)$ was also significantly greater than in the PBO group, and the median time to failure was significantly longer (36 weeks; $\mathrm{p}<0.001)$. Two additional post hoc summaries (which could be considered sensitivity analyses) were performed. In the first, the primary outcome was summarised only for those patients who at randomisation were in DAS28-defined remission (DAS28<2.6). In this summary, 3 out of 18 patients $(17 \%)$ in the PBO group, 11 out of 21 patients $(52 \%)$ in the ETN25 group and 12 out of 20 patients $(60 \%)$ in the ETN50 group were non-failures. In the second, the patients were categorised according to MTX dose at baseline: 55 out of 73 patients were on $\leq 15 \mathrm{mg}$ weekly MTX, and in these patients the proportions of non-failures in the three arms were similar to the primary outcome $(12 / 21,15 \% ; 9 / 21$, $43 \%$; 2/13, 57\%); the remaining 18 patients who were on higher dosages of MTX yielded subgroups too small for summaries to be interpretable.

The majority of patients who had failed during period 2 regained $\mathrm{LDA} /$ remission rapidly when retreated with ETN $50 \mathrm{mg}+$ MTX during period 3 (91\%; figure 3B). Median times from failure to LDA/remission were similar for the ETN50 (6.0 weeks), ETN25 (5.9 weeks) and PBO (3.9 weeks) groups.

\section{Predictors of treatment failure}

Results are presented in the online supplementary text and table S1.

\section{Adverse events}

AEs were consistent with the patient population and known side effects of ETN and MTX. During period 1, 27 patients (30\%) experienced 35 AEs, none of which were considered severe and did not meet the regulatory definition of serious (see online supplementary table S2). Four of these AEs were considered related to study treatment; none led to discontinuation or withdrawal. In the second phase, 43 of the 73 randomised patients $(59 \%)$ experienced at least one AE, with a total of 152 AEs reported; 22 patients had AEs considered related to study treatment. In period 2, two patients (3\%) reported a serious AE. One of these was a patient in the ETN25 group with severe endometritis that was considered related to the study treatment and led to withdrawal but was resolved 17 days later. The other serious $\mathrm{AE}$ was back pain, reported in a patient from the ETN50 group, which was resolved 50 days later and not considered related to the study treatment. Similar rates of AEs were observed between the active treatment groups in periods 2 and 3. In period 3, one patient (2\%) experienced pyrexia, a serious AE considered related to the study treatment that was resolved 18 days later. No deaths occurred during the course of the study. Additional safety results are provided in the online supplementary text.

\section{DISCUSSION}

In this randomised, double-blinded study, we have shown that in patients with established RA who have achieved stable LDA with ETN50+MTX continuation of such treatment to maintain response is superior to $\mathrm{PBO}+\mathrm{MTX}$. In addition, maintenance treatment with the reduced dose ETN was also more effective than PBO. These results support those observed in PRESERVE. ${ }^{20}$ In the countries where this study was performed, the treatment combination of ETN+MTX typically requires moderate or severe RA disease activity and failure to respond to at least one, but usually several, conventional antirheumatic agent. Thus, our patient population represents more severe and refractory disease, in contrast to the moderate disease activity population in PRESERVE.

While only a small majority of patients with sustained dose ETN and fewer with reduced dose ETN maintained LDA for 48 weeks, this study still demonstrates that in patients with established RA who achieved LDA on ETN+MTX discontinuing the maintenance treatment with ETN is associated with a much higher risk of disease flare than continued treatment. Failure in this study was defined as both an increase in DAS28 by $\geq 0.6$ (minimal clinically important difference based on prior studies $^{21}{ }^{22}$ ) and an absolute value $>3.2$ (the cut-off between low and moderate disease activity), or the investigator's/patient's assessment of the disease. This criterion was chosen to avoid classing patients as failures when they had either an increase in their DAS28 but still remained in the LDA state, or had a change less than the minimal clinically important difference. However, as a trade-off, we accepted that some patients might have a smaller increase in the DAS28 but end up having a DAS28 $>3.2$ (eg, increasing from DAS28 value 2.9 to 3.3 ) and such patients would not be classified as failures. In order to avoid the serious ethical problem that patients might truly experience a flare in disease activity but not be classed as failures because of limitations inherent in the measurements used (eg, DAS28 does not include the ankles and feet and does not reflect the grade of inflammation in the individual joints), we also specifically allowed patients to contact the investigators if they experienced a flare. This occurred in four patients within each treatment group, and they were classified as failures and subsequently entered into period 3 of the study.

The secondary outcomes for the ETN25 group must be interpreted with caution. ETN25 was shown to be superior to PBO, whereas the difference between ETN25 and ETN50 was modest. However, the study was not powered to demonstrate a difference or equivalence between these two doses and a true difference cannot be ruled out (a type 2 error). In addition, baseline DAS28 was numerically higher although non-significant in the ETN25 group, and this may have affected the outcome. Notwithstanding these limitations, we believe our results are important for two reasons. First, from a theoretical point of view, these clinical results represent the first controlled demonstration that an induction maintenance strategy can be applied in some patients with established RA for whom the use of anti-TNF is clinically necessary. Second, from a clinical practice point of view, these results suggest that in some patients it may be possible to reduce dosages while maintaining the same favourable disease state. MTX remained stable throughout; therefore, any differences in outcomes could not be explained by changes in the MTX dose.

The primary analysis was the proportion of patients who were non-failures after 48 weeks, and the results indicated that a lower-than-expected proportion of patients who continued fulldose ETN were non-failures. However, in line with expectations, this proportion was significantly greater than in those who discontinued ETN. Thus, the proportion of patients considered failures was higher than anticipated. This is particularly notable in the patients who continued with unchanged therapy (ETN50) where prior studies and widespread clinical experience suggest that they would normally maintain the response during a given time period of 1 year. One possible explanation for this apparent anomaly is that when patients are observed frequently (in this study, every six weeks) and with attention to potential flares, a greater amount of fluctuation in variables such as tender and swollen joints will be present than in the normal longitudinal follow-up situation, whether in clinical practice or in an 


\section{Clinical and epidemiological research}

Figure 3 (A) Kaplan-Meier (KM) plot of the time from randomisation to failure in period 2. (B) KM plot showing time from failure to LDA/ remission in period 3.

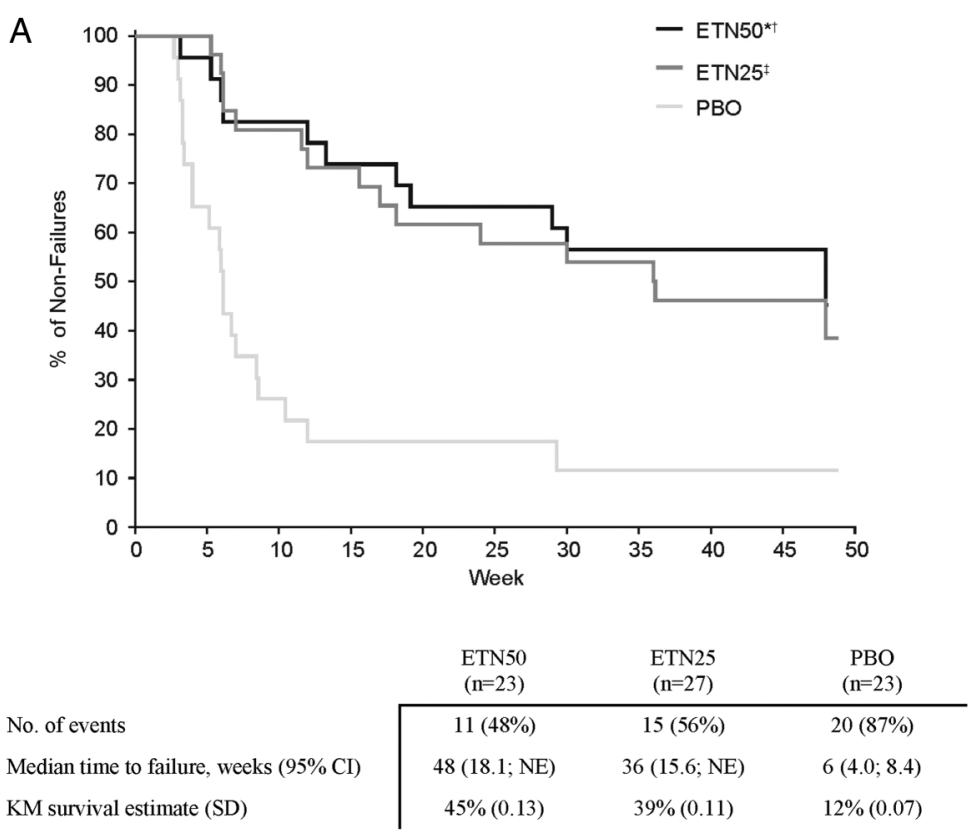

*HR $0.24\left(95 \%\right.$ CI, 0.10-0.56), $\mathrm{P}=0.001$ vs. PBO; ${ }^{\dagger} \mathrm{HR} 1.01$ (95\% CI, 0.43-2.35), $\mathrm{P}=0.988$ vs ETN25; ${ }^{\dagger} \mathrm{HR} 0.23$ (95\% CI, 0.11-0.51), P<0.001 vs. PBO.

mITT population used. $\mathrm{P}$ values calculated using a Cox Model. Median time to failure is the estimated time where $50 \%$ of patients will have failed and takes into account censored patients. ETN, etanercept; MTX, methotrexate; PBO, placebo; NE, not evaluable.

$\mathrm{B}$

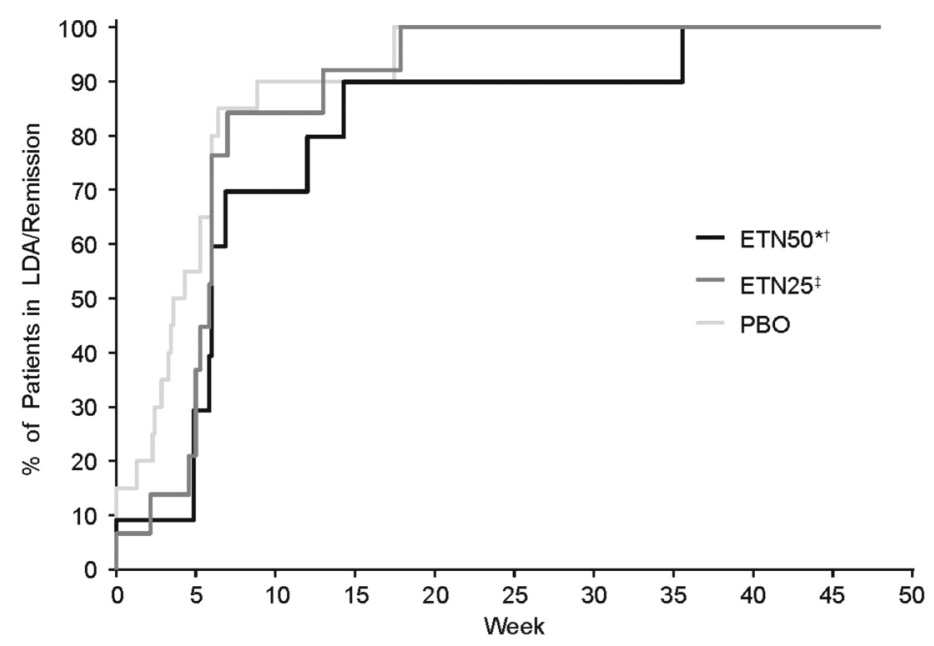

No. of events

Median time to LDA/remission, weeks $(95 \% \mathrm{CI})^{*}$

KM survival estimate (SD)

\begin{tabular}{|ccc}
\multicolumn{1}{c}{$\begin{array}{c}\text { ETN50 } \\
(\mathbf{n = 1 1})\end{array}$} & $\begin{array}{c}\text { ETN25 } \\
(\mathbf{n = 1 5})\end{array}$ & $\begin{array}{c}\text { PBO } \\
(\mathbf{n}=\mathbf{2 0})\end{array}$ \\
\hline $10(91 \%)$ & $13(87 \%)$ & $19(95 \%)$ \\
$6.0(4.9 ; 12.0)$ & $5.9(4.6 ; 6.0)$ & $3.9(2.3 ; 6.0)$ \\
$100 \%(\mathrm{NE})$ & $100 \%(\mathrm{NE})$ & $100 \%(\mathrm{NE})$ \\
\hline
\end{tabular}

${ }^{*} \mathrm{HR} 0.37$ (95\% CI, 0.12-1.11), $\mathrm{P}=0.076$ vs. PBO; ${ }^{\dagger} \mathrm{HR} 0.53$ (95\% CI, 0.15-1.91), $\mathrm{P}=0.332$ vs. ETN25; ${ }^{\dagger} \mathrm{HR} 0.69$ (95\% CI, 0.28-1.71), P=0.422 vs. PBO

mITT population used. $\mathrm{P}$ values calculated using a Cox Model. Median time to LDA/remission is the estimated time where $50 \%$ of patients will have returned to LDA/remission and takes into account censored patients. ETN, etanercept; MTX, methotrexate; PBO, placebo; NE, not evaluable. 
uncontrolled clinical trial. While such fluctuations mostly occur as random variations, some may have sufficient magnitude to achieve the threshold for flare as chosen for this study. This same mechanism may have been responsible for the relatively large proportion of patients who did not maintain LDA during period 1.

For this study, we chose to use LDA as the clinical disease activity state of interest, implicitly indicating that this was desirable and sufficient for this patient group. It could be argued, based, for example, on the treat-to-target guidelines, the European League Against Rheumatism and American College of Rheumatology RA treatment recommendations, ${ }^{23-25}$ that a patient population in remission (DAS28 $\leq 2.6$, or by an even more stringent definition) would be more appropriate. In fact, $59(82 \%)$ patients had a DAS28 $\leq 2.6$ at randomisation. However, in the population most likely to be treated with ETN in clinical practice, that is, in patients with established RA, LDA has also been considered a reasonable treatment goal according to these treatment guidelines. Similarly, the objective of this study was to determine whether a favourable disease state achieved by MTX+ETN can be maintained by MTX or MTX + ETN at half dose. Although it may be more intuitive to apply this question to the patient in remission, it can also be asked for the patient who has achieved LDA and in whom further improvement is not considered possible.

An important clinical question is whether ETN at $25 \mathrm{mg}$ weekly can in some patients be 'as good as' $50 \mathrm{mg}$ weekly. While the current trial may provide suggestions in this regard, the most convincing method to address this issue would be a non-inferiority randomised clinical trial where patients in a stable and favourable disease state are randomly assigned to one of those two dosages. The trial reported here provides data that may inform such a future study.

ETN is not approved at doses other than $50 \mathrm{mg}$ weekly (in one single or two divided dosages) for the treatment of adults with RA. A dose reduction is therefore not supported by the product label and also entails some practical difficulties. Various uncontrolled observational studies have suggested that a prolonged treatment interval may be effective for some patients as maintenance therapy. ${ }^{15}{ }^{19}$ While pharmacokinetically these two options are not entirely equivalent, these experiences suggest that for some patients a more simplified ETN treatment regimen might indeed be feasible. However, in view of the current findings and other results, we would not advocate reduction of medication in a patient with LDA who obviously still has ongoing disease activity.

A specific concern with discontinuation studies is the risk that a flare following discontinuation may not be fully reversible. A classic study on discontinuation of conventional antirheumatics clearly demonstrated that this was the case for such medications (mostly intramuscular gold salts). ${ }^{26} \quad 27$ The study performed by Botsios et $a l^{15}$ suggested that remission or LDA could be recaptured in some but not all patients. In our study, 91\% of patients who were declared failures went on to recapture LDA quickly when resuming full-dose ETN under openlabel conditions, providing a measure of reassurance on this point. The remaining $9 \%$ of patients were censored, meaning that at week 48 they had yet to return to LDA/remission. This could have been due to the patients not being in period 3 long enough to reach $\mathrm{LDA} /$ remission.

Anti-TNF agents are considerably more expensive than conventional antirheumatic drugs, and as a class have exerted considerable pressures on medication budgets, whether at the individual, health insurance or national health plan levels. The finding that a reduced dosage of an anti-TNF agent could be effective as maintenance therapy is, if confirmed, important from a pharmacoeconomic point of view. However, a full assessment of this possibility would require considerably more robust data in a larger population on the full clinical as well as radiographic effects, both short term and long term, of such therapy. Moreover, it is not possible to know whether these data would apply equally to other anti-TNF agents.

The main strengths of this study are the double-blinded randomised design of period 2 and a strict adherence to the protocol ensured through 100\% monitoring. The study also examines a question of considerable theoretical and practical importance. The main weakness of the study is its limited size and associated wide CIs. This results in uncertainty regarding the comparison of the clinical efficacies of full-dose and reduced dose ETN continuation.

Other weaknesses include the documentation of stable LDA prior to study inclusion could have 'missed' flares that occurred between documented points in time. It is for this reason we chose to include an 8-week run-in period. In addition, we had limited knowledge of the patients' disease state prior to the original initiation of ETN therapy.

In summary, patients with established RA who were given ETN + MTX in actual clinical practice and achieved LDA, continuation with ETN either at the full dose or at half dose was significantly superior to discontinuation. Patients who flared were able to recapture response quickly and effectively with ETN retreatment.

\section{Author affiliations}

${ }^{1}$ Unit for Clinical Therapy Research, Inflammatory Diseases (ClinTRID), the Karolinska Institute, Stockholm, Sweden

${ }^{2}$ Rheumatology Clinic, Karolinska University Hospital, Stockholm, Sweden

${ }^{3}$ Faculty of Health Sciences, Copenhagen Center for Arthritis Research, Centre for Rheumatology and Spine Diseases, Glostrup Hospital, University of Copenhagen, Copenhagen, Denmark

${ }^{4}$ Helsinki University Central Hospital, and Institute of Clinical Medicine, University of Helsinki, Helsinki, Finland

${ }^{5}$ National Advisory Unit on Rehabilitation in Rheumatology, Department of Rheumatology, Diakonhjemmet Hospital, Oslo, Norway

${ }^{6}$ Pfizer Sweden, Sollentuna, Sweden

${ }^{7}$ Statistical Consultancy, Quanticate, Hitchin, UK

${ }^{8}$ Department of Medical Sciences, University of Uppsala, Uppsala, Sweden

Acknowledgements We would like to thank all participating patients, as well as the study nurses, co-investigators and colleagues, who made this study possible.

Contributors All authors made a substantial contribution to study concept and design, or data acquisition, analysis and/or interpretation; drafted the article or revised it critically for important intellectual content; approved the final version to be submitted/published; and agreed to be accountable for all aspects of the work in ensuring that questions related to the accuracy or integrity of any part of the work are appropriately investigated and resolved. RFvV: study concept, study design, data acquisition, data interpretation, first draft of the article, revisions of the article and final approval. MØ, TU, ML-R, MJ and KF-L: study concept, study design, data acquisition, data interpretation, revisions of the article and final approval. FB: data analysis, data interpretation, revisions of the article and final approval. EL: data interpretation, revisions of the article and final approval.

Funding This study was sponsored by Wyeth, which was acquired by Pfizer in October 2009. The academic authors and some other investigators had designed the main features of the protocol prior to the agreement by Wyeth to support this study. The corresponding authors had full access to all the data in the study and had final responsibility for the decision to submit for publication. Editorial support was provided by Kim Brown of Engage Scientific Solutions and was funded by Pfizer.

Competing interests RFvV has received research support and honoraria from AbbVie (Abbott), BMS, GSK, Lilly, MSD, Pfizer, Roche, and UCB Pharma. MØ has received research support and/or honoraria from AbbVie (Abbott), BMS, Centocor, GSK, Janssen, Merck, Mundipharma, Novo, Pfizer, Schering-Plough, Roche, UCB and Wyeth. TU has received research support and honoraria from AbbVie (Abbott), BMS, MSD, Pfizer, Roche and UCB Pharma. ML-R has been a consultant for Abbott, Pfizer, MSD, Roche and BMS. EL and MJ were employees of Pfizer Sweden at the 
time of the study; EL is currently an employee of Eli Lilly. FB is an employee of Quanticate who were paid consultants to Pfizer in connection with statistical support for the development of this manuscript. KF-L was an employee of Wyeth/Pfizer at the time of the conduct of the study and is currently employed by the Swedish Medical Products Agency.

Ethics approval Institutional Review Board(s) and/or Independent Ethics Committee(s) at each of the investigational centres participating in the study.

Provenance and peer review Not commissioned; externally peer reviewed.

Open Access This is an Open Access article distributed in accordance with the Creative Commons Attribution Non Commercial (CC BY-NC 4.0) license, which permits others to distribute, remix, adapt, build upon this work non-commercially, and license their derivative works on different terms, provided the original work is properly cited and the use is non-commercial. See: http://creativecommons.org/ licenses/by-nc/4.0/

\section{REFERENCES}

1 Abdel-Nasser AM, Rasker JJ, Valkenburg HA. Epidemiological and clinical aspects relating to the variability of rheumatoid arthritis. Semin Arthritis Rheum 1997;27:123-40.

2 Hochberg MC, Spector TD. Epidemiology of rheumatoid arthritis: update. Epidemiol $\operatorname{Rev} 1990 ; 12: 247-52$

3 Kvien TK, Uhlig T, Odegard S, et al Epidemiological aspects of rheumatoid arthritis: the sex ratio. Ann N Y Acad Sci 2006;1069:212-22.

4 Scott DL, Wolfe F, Huizinga TW. Rheumatoid arthritis. Lancet 2010;376:1094-108.

5 Welsing PM, van Gestel AM, Swinkels HL, et al The relationship between disease activity, joint destruction, and functional capacity over the course of rheumatoid arthritis. Arthritis Rheum 2001;44:2009-17.

6 Drossaers-Bakker KW, de Buck M, van Zeben D, et al Long-term course and outcome of functional capacity in rheumatoid arthritis: the effect of disease activity and radiologic damage over time. Arthritis Rheum 1999:42:1854-60.

7 Cooper NJ. Economic burden of rheumatoid arthritis: a systematic review. Rheumatology 2000;39:28-33.

8 Michaud K, Messer J, Choi HK, et al Direct medical costs and their predictors in patients with rheumatoid arthritis: a three-year study of 7,527 patients. Arthritis Rheum 2003:48:2750-62.

9 Weinblatt ME, Kremer JM, Bankhurst AD, et al. A trial of etanercept, a recombinant tumor necrosis factor receptor:Fc fusion protein, in patients with rheumatoid arthritis receiving methotrexate. N Engl J Med 1999;340:253-9.

10 Moreland LW, Schiff MH, Baumgartner SW, et al. Etanercept therapy in rheumatoid arthritis. A randomized, controlled trial. Ann Intern Med 1999;130:478-86.

11 Klareskog L, van der Heijde D, de Jager JP, et al. Therapeutic effect of the combination of etanercept and methotrexate compared with each treatment alone in patients with rheumatoid arthritis: double-blind randomised controlled trial. Lancet 2004;363:675-81.

12 Emery P, Breedveld FC, Hall S, et al. Comparison of methotrexate monotherapy with a combination of methotrexate and etanercept in active, early, moderate to severe rheumatoid arthritis (COMET): a randomised, double-blind, parallel treatment trial. Lancet 2008;372:375-82.

13 Bathon JM, Martin RW, Fleischmann RM, et al. A comparison of etanercept and methotrexate in patients with early rheumatoid arthritis. $N$ Engl I Med 2000;343:1586-93.

14 van der Heijde D, Klareskog L, Landewe R, et al. Disease remission and sustained halting of radiographic progression with combination etanercept and methotrexate in patients with rheumatoid arthritis. Arthritis Rheum 2007;56:3928-39.

15 Botsios C, Furlan A, Ostuni P, et al. Effects of low-dose etanercept in maintaining DAS-remission previously achieved with standard-dose in patients with rheumatoid arthritis. Ann Rheum Dis 2007;66(Suppl II):54.

16 Brocq $\mathrm{O}$, Millasseau E, Albert $\mathrm{C}$, et al. Effect of discontinuing TNFalpha antagonist therapy in patients with remission of rheumatoid arthritis. Joint Bone Spine 2009;76:350-5.

17 Saleem B, Keen H, Goeb V, et al. Patients with RA in remission on TNF blockers: when and in whom can TNF blocker therapy be stopped? Ann Rheum Dis 2010;69:1636-42.

18 Tanaka Y, Takeuchi T, Mimori T, et al. Discontinuation of infliximab after attaining low disease activity in patients with rheumatoid arthritis: RRR (remission induction by Remicade in RA) study. Ann Rheum Dis 2010;69:1286-91.

19 Fautrel B, Pham T, Tubach F. Tapering TNF-blockers in established rheumatoid arthritis patients in DAS28 remission: Results of a DAS28-driven step-down strategy randomized controlled trial. Arthritis Rheum 2012;64:4169.

20 Smolen JS, Nash P, Durez P, et al. Maintenance, reduction, or withdrawal of etanercept after treatment with etanercept and methotrexate in patients with moderate rheumatoid arthritis (PRESERVE): a randomised controlled trial. Lancet 2013;381:918-29.

21 Fransen J, van Riel PL. The disease activity score and the EULAR response criteria. Clin Exp Rheumatol 2005;23:593-9.

22 van Gestel AM, Haagsma CJ, van Riel PL. Validation of rheumatoid arthritis improvement criteria that include simplified joint counts. Arthritis Rheum 1998;41:1845-50.

23 Smolen JS, Aletaha D, Bijlsma JW, et al. Treating rheumatoid arthritis to target: recommendations of an international task force. Ann Rheum Dis 2010;69: $631-7$.

24 Singh JA, Furst DE, Bharat A, et al. 2012 update of the 2008 American College of Rheumatology recommendations for the use of disease-modifying antirheumatic drugs and biologic agents in the treatment of rheumatoid arthritis. Arthritis Care Res (Hoboken) 2012;64:625-39.

25 Smolen JS, Landewe R, Breedveld FC, et al. EULAR recommendations for the management of rheumatoid arthritis with synthetic and biological disease-modifying antirheumatic drugs. Ann Rheum Dis 2010;69:964-75.

26 ten Wolde S, Breedveld FC, Hermans J, et al. Randomised placebo-controlled study of stopping second-line drugs in rheumatoid arthritis. Lancet 1996;347:347-52.

27 ten Wolde S, Hermans J, Breedveld FC, et al. Effect of resumption of second line drugs in patients with rheumatoid arthritis that flared up after treatment discontinuation. Ann Rheum Dis 1997:56:235-9. 